\title{
A potential application for the intracerebral injection of drugs entrapped within liposomes in the treatment of human cerebral gliomas
}

\author{
RONALD O MCKERAN, ${ }^{*}$ GARY FIRTH,† SPENCER OLIVER,‡ DAVID UTTLEY, ${ }^{*}$ \\ SEAN O'LAOIRE*
}

From Atkinson Morley's Hospital, Wimbledon, ${ }^{*}$ Biochemistry Department, St George's Hospital Medical School, London, $¥$ and Hurstwood Park Neurological Centre, Department of Biochemistry, Sussex and University of Surrey, $\dagger U K$

SUMMARY After intravenous injection of therapeutic doses of bleomycin only small amounts could be measured in glioma tissue obtained at operation in patients with malignant gliomas and the drug was rapidly cleared from the blood $\left(\mathrm{T}_{1 / 2}=2 \mathrm{hrs}\right)$. Negatively charged liposomes injected through Ommaya reservoirs into the glioma tumour bed were tolerated without observable side effect. The appearance of bleomycin in the blood and urinary clearance after intracerebral injection of bleomycin entrapped within negatively charged liposomes through an Ommaya reservoir in patients with malignant gliomas was decreased as compared with levels when free bleomycin was injected. These preliminary observations suggest a role of drugs entrapped within liposomes as a depot preparation in the treatment of human cerebral gliomas.

Surgery, radiotherapy and more recently chemotherapy and immunotherapy have improved the outcome in the treatment of human cerebral gliomas to some extent but the sad fact remains that the condition is still uniformly fatal with poorly differentiated gliomas having a reported median survival time of 5-13 months.' Lipid soluble drugs which readily cross the normal blood-brain barrier have been found to be generally more effective than those which are less lipid soluble and more often cell-cycle specific. This is particularly unfortunate since in no other type of cancer is there such a clear kinetic difference between the tumour and the normal tissue with respect to its cell division rate. ${ }^{2}$ If cell cycle specific drugs could be delivered in an effective and sustained concentration a good differential response might be anticipated. However to achieve a significant concentration of drug for a therapeutically adequate period of time in the central core of a $6 \mathrm{~cm}$ diameter glioblastoma multiforme at a depth of

Address for reprint requests: Dr RO McKeran, Department of Neurology, Atkinson Morley's Hospital, 31 Copse Hill, Wimbledon, SW20 ONE, UK.

Received 2 October 1984 and in revised form 12 May 1985. Accepted 17 May 1985
$1-3 \mathrm{~cm}$ from the perfused rim, it has been calculated that a therapeutic plasma level of drug would have to be maintained for 10-24 h. ${ }^{3}$ Since many of the cell cycle specific drugs have relatively short half lives after intravenous injection to maintain sustained therapeutic levels of drug in the blood would result in unacceptable side effects.

Local injection of antimitotic drugs into cerebral tumours has been used but the vascularity of the glioma tissue bed is such that high enough concentrations of drug cannot be sustained for an adequate period of time. ${ }^{4}$ These considerations suggest that an inert depot preparation of antimitotic drug injected locally into the tumour mass with sustained release of drug might be more effective than a similar dose of drug given systemically and should enable a higher dose of drug to be given without the appearance of systemic toxicity.

We have recently determined the optimal conditions for producing the maximum incorporation within negatively charged liposomes of two relatively cell cycle specific drugs (bleomycin and vincristine) used in the treatment of human cerebral gliomas. ${ }^{5}$ A delayed release of these drugs from the liposomes was demonstrated and dose response curves were similar for the two drugs whether given as the free or liposome entrapped drug to a human 
glioma cell line (U251-MG). Subsequent studies on the intracerebral injection of bleomycin free and entrapped within liposomes in the rat demonstrated no detectable cerebral toxicity after injection of liposomes, and a delayed clearance of the drug from the injection site when given entrapped within liposomes rather than as the free drug. ${ }^{6}$ A similar delayed cerebral clearance was demonstrated with vincristine although when given either as the free or liposome entrapped drug cerebral toxicity was present. ${ }^{7}$ These animal experiments have suggested a potential application for drugs entrapped within liposomes acting as a depot preparation in the treatment of human cerebral gliomas. We have now extended these studies to human subjects with malignant gliomas and report our preliminary observations.

\section{Patients and methods}

\section{Materials}

Cholesterol, dipalmitoyl phosphatidylcholine and dipalmitoyl phosphatidic acid of highest obtainable purity were purchased from Sigma Chemical Company. Bleomycin was kindly donated by Lundbeck Ltd. Sepharose 6B was obtained from Pharmacia Ltd. Bleomycin antisera and donkey antisheep serum were obtained from Guildhay, University of Surrey. ${ }^{125}$ I was obtained from Amersham International. All other reagents were obtained through BDH Ltd.

\section{Methods}

Iodination and radioimmunoassay (RIA) of bleomycin. Iodination was performed using the method of Salacinski et al. ${ }^{8}$ The RIA was performed as previously described. ${ }^{6}$ The technique had an interassay coefficient of variation of $3.5 \%$ and an intra-assay coefficient of variation of $7.5 \%$ at a level of $50 \mathrm{ng} /$ $\mathrm{ml}$, and a detection limit of $40 \mathrm{pg}$, per tube.

Preparation of liposomes Liposomes were prepared by the reverse phase method described by Szoka and Papahadjopoulos. ${ }^{9}$ Standard sterile tech- niques were adopted throughout. Samples from each preparation were sent for microbiological examination and cultured for $48 \mathrm{~h}$ prior to human intracerebral injection, during which time the liposomes were stored at $4^{\circ} \mathrm{C}$ to reduce the rate of release of free drug. ${ }^{5}$ At the time of human administration the amount of free drug released from the liposomes was determined in an aliquot by separation on sepharase 6B.

Assay of bleomycin in human cerebral glioma tissue In four patients with malignant gliomas (Grade IV astrocytomas) and one with a cerebral secondary deposit, cerebral tumour tissue at different depths was taken at routine craniotomy for the surgical treatment of the tumour 15 and 30 mins after intravenous injection of $10 \mathrm{mg}$ of bleomycin. The tumour was immediately stored at $-20^{\circ} \mathrm{C}$ until assayed for bleomycin. The specimens were homogenised in an $0.05 \mathrm{M} \mathrm{pH} 7.4$ phosphate buffer using a glass hand held homogeniser and assayed by RIA for bleomycin. Concentrations were expressed in terms of concentration of bleomycin $/ \mathrm{mg}$ of wet tumour tissue.

Patients These studies have been approved by St George's Hospital District Ethical Committee. Three patients with malignant cerebral gliomas were studied. Blood levels and the urinary clearance of bleomycin after intravenous injection of 5,10 and $15 \mathrm{mg}$ of bleomycin were determined in subject 1 over $24 \mathrm{~h}$. In subject 2 the blood levels and urinary clearance of bleomycin after intravenous injection of free and liposome entrapped drug was studied over $6 \mathrm{~h}$. Negatively charged liposomes were injected through an Ommaya reservoir inserted at previous craniotomy into the tumour bed in subject 1 and her behaviour carefully monitored over a 2 week period. Increasing amounts of free bleomycin were injected through an Ommaya reservoir and blood and urine levels measured over $18 \mathrm{~h}$ in subject 3. Liposome entrapped bleomycin was injected through an Ommaya reservoir into the tumour bed in subjects 1 and 3 , and blood and urine levels of drug determined.

Table 1 Tumour levels of bleomycin following intravenous injection of $10 \mathrm{mg}$ bleomycin

\begin{tabular}{|c|c|c|c|c|c|c|}
\hline & \multicolumn{6}{|c|}{ ng bleomycin/mg wet wt brain tissue } \\
\hline & \multicolumn{4}{|c|}{$\begin{array}{l}\text { Surrounding margin of macroscopically Viable tumour } \\
\text { normal tissue }\end{array}$} & \multicolumn{2}{|c|}{ Necrotic centre of the tumou } \\
\hline & $15 \min$ & $30 \min$ & $15 \mathrm{~min}$ & $30 \min$ & $15 \min$ & $30 \min$ \\
\hline $\begin{array}{l}\text { Patient A } \\
\text { Patient B } \\
\text { Patient C } \\
\text { Patient D } \\
\text { Patient E }\end{array}$ & $\begin{array}{r}<0.03 \\
0.09 \\
<0.10 \\
<0.05 \\
0.66\end{array}$ & $\begin{array}{r}<0.03 \\
0.11 \\
0.12 \\
0.43 \\
0.41\end{array}$ & $\begin{array}{r}-0.23 \\
0.29 \\
<0.06 \\
-\end{array}$ & $\begin{array}{l}- \\
0 \cdot 26 \\
0 \cdot 21 \\
0 \cdot 48 \\
-\end{array}$ & $\begin{array}{l}0.13 \\
0.19 \\
0.13 \\
<0.2 \\
0.24\end{array}$ & $\begin{array}{l}0.13 \\
0.12 \\
0.19 \\
0.42 \\
0.21\end{array}$ \\
\hline
\end{tabular}


Intracerebral injection of drugs entrapped within liposomes in the treatment of human cerebral gliomas 1215

Table 2 Peak serum bleomycin levels achieved following injection of bleomycin, free and entrapped within liposomes

\begin{tabular}{|c|c|c|c|c|}
\hline \multirow{3}{*}{$\begin{array}{l}\text { Dose of bleomycin } \\
\text { injected }(\mathrm{mg})\end{array}$} & \multicolumn{4}{|c|}{ Serum bleomycin $(\mathrm{ng} / \mathrm{ml})$} \\
\hline & \multicolumn{2}{|c|}{ Intravenous injection ${ }^{*}$} & \multicolumn{2}{|c|}{ Intracerebral injection } \\
\hline & Free & Entrapped & Free & Entrapped \\
\hline $\begin{array}{l}0.1 \mathrm{mg} \\
0.45 \mathrm{mg} \\
2 \mathrm{mg} \\
3.3 \mathrm{mg} \\
5 \mathrm{mg} \\
6 \mathrm{mg} \\
10 \mathrm{mg} \\
15 \mathrm{mg}\end{array}$ & $\begin{array}{r}617^{2} \\
500^{1} \\
1200^{1} \\
2034^{1}\end{array}$ & $108^{2}$ & $\begin{array}{r}2 \cdot 6^{3} \\
4 \cdot 6^{3} \\
41 \cdot 5^{3} \\
\\
66 \cdot 0^{3}\end{array}$ & $\begin{array}{l}<1 \cdot 0^{1} \\
1 \cdot 1^{3} \\
3 \cdot 6^{3} / 4 \cdot 0^{3}\end{array}$ \\
\hline
\end{tabular}

${ }^{*}$ Levels achieved 5 minutes after intravenous injection.

$1=$ Patient $1,2=$ Patient 2, $3=$ Patient 3.

Table 324 hour urinary excretion of bleomycin following injection of bleomycin, free and entrapped within liposomes

\begin{tabular}{|c|c|c|c|c|}
\hline \multirow{3}{*}{$\begin{array}{l}\text { Dose of bleomycin } \\
\text { injected (mg) }\end{array}$} & \multicolumn{4}{|c|}{24 hour urinary bleomycin excretion (\% of total) } \\
\hline & \multicolumn{2}{|c|}{ Intravenous injection } & \multicolumn{2}{|c|}{ Intracerebral injection } \\
\hline & Free & Entrapped & Free & Entrapped \\
\hline $\begin{array}{l}0.1 \mathrm{mg} \\
0.45 \mathrm{mg} \\
2 \mathrm{mg} \\
3.3 \mathrm{mg} \\
5 \mathrm{mg} \\
6 \mathrm{mg} \\
10 \mathrm{mg} \\
15 \mathrm{mg}\end{array}$ & $\begin{array}{l}91^{2} \\
80^{1} \\
\\
86^{1} \\
75^{1}\end{array}$ & $39 \cdot 5^{2}$ & $\begin{array}{l}12^{3} \\
26 \cdot 5^{3} \\
79 \cdot 5^{3} \\
60 \cdot 0^{3}\end{array}$ & $\begin{array}{l}\mathrm{ND}^{1} \\
11 \cdot 1^{3} \\
11 \cdot 2^{3} / 18 \cdot 6^{3}\end{array}$ \\
\hline
\end{tabular}

ND $=$ Not detected

$1=$ Patient $1,2=$ Patient 2, 3 = Patient 3.

\section{Results}

Tumour levels of bleomycin after intravenous injection

The tumour levels of bleomycin at different depths in the tumour after intravenous injection of $10 \mathrm{mg}$ of bleomycin 15 and 30 mins before sampling are shown in table 1 . In the subject with a cerebral secondary the lowest levels of bleomycin were found probably owing to the known presence of a bleomycin hydrolase in these non-ectodermally derived neoplastic cells. ${ }^{10}$ With one exception there was no difference in the amount of bleomycin which had permeated the tumour tissue at 30 as compared with 15 mins. The highest concentration of drug was found in the area of viable tumour as compared with the surrounding margin of macroscopically normal tissue or the necrotic centre of the tumour. The concentration of drug achieved in the tumour was between $1 / 4$ and $1 / 2$ that obtained in blood at 30 mins.

Blood and urine levels of bleomycin achieved after intravenous injection in subject 1 of the free drug and in subject 2 of both the free and liposome entrapped drug.

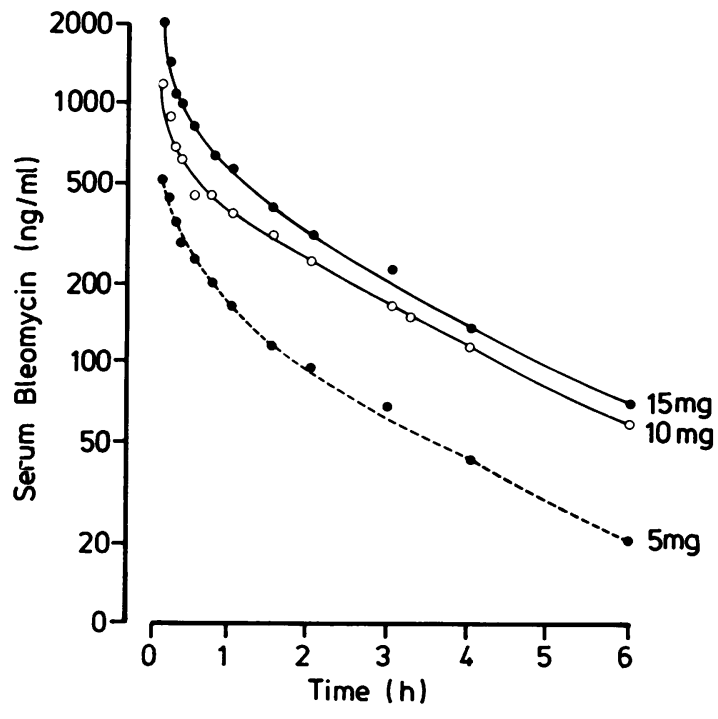

Fig.1 Bleomycin clearance from blood following intravenous injection in a human subject with a malignant cerebral glioma (patient 1). 


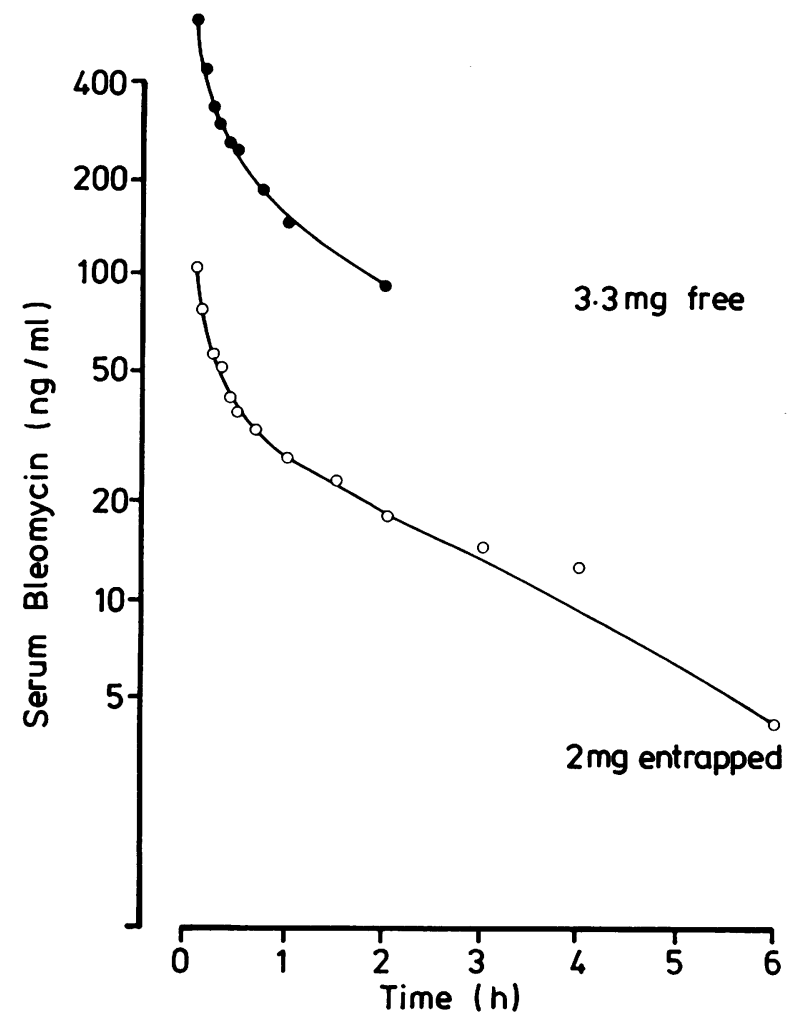

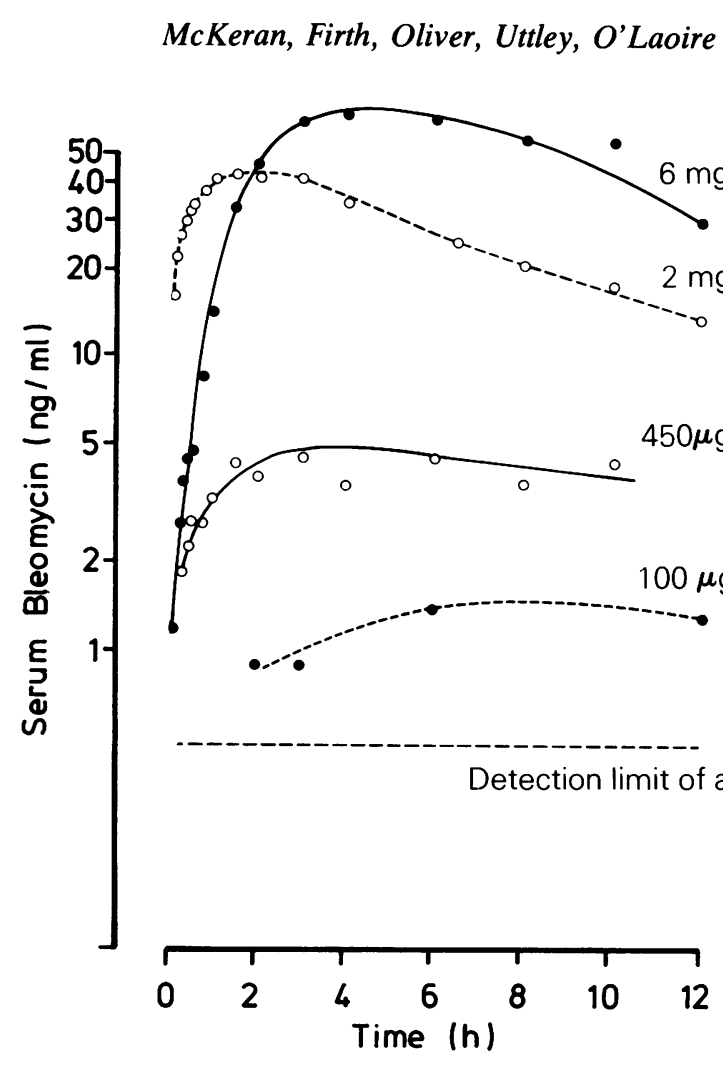

Fig. 3 Serum bleomycin levels following intracerebral injection of free bleomycin in a subject with malignant gliomas (patient 3).
Fig. 2 Serum bleomycin levels following intravenous injection of bleomycin free and entrapped within liposomes in a subject with a malignant glioma (patient 2).

The blood and urine levels of bleomycin achieved after intravenous injection of 5,10 and $15 \mathrm{mg}$ of bleomycin in subject 1 are shown in Figure 1 and tables 2 and 3 . The drug $T_{1 / 2}$ in blood was $112 \mathrm{~min}$ (range $110-116 \mathrm{~min}$ ) and urinary clearance $80 \%$ (range $75-86 \%$ ) at $24 \mathrm{~h}$.

In subject 2 the peak level in the blood after intravenous injection of bleomycin entrapped within liposomes was considerably less than when the free drug was given (fig 2) and the urinary clearance approximately half that obtained with the free drug ( $40 \%$ as compared to $91 \%$ at $24 \mathrm{~h}$ ).

\section{Blood and urine levels of bleomycin after} intracerebral injection of bleomycin free and entrapped within liposomes through an Ommaya reservoir in subjects 1 and 3 .

No adverse effect was recorded clinically in subjects 1 and 3 over a total period of 4 weeks observation which could be attributed to the effect of injecting negatively charged liposomes into the tumour. Their conscious level, the clinical evidence of raised intracranial pressure and focal neurological deficits remained unaltered and they recorded no headache or drowsiness and no temperature or seizures were witnessed.

The blood levels and urinary excretion of bleomycin after the injection of the free drug through the Ommaya reservoir into the tumour in subject 3 is shown in figs. 3 and 5. The urinary clearance of bleomycin increased as the amount of drug injected increased and at $6 \mathrm{mg}$ approached the levels recorded after intravenous injection of free drug. Blood and urine levels of bleomycin after injection of the liposome entrapped drug through an Ommaya reservoir into the tumour in subjects 1 and 3 are shown in figs 4 and 5 . With $100 \mu$ g of bleomycin entrapped within liposomes no blood level or urinary clearance could be demonstrated although this was possible after the intratumour injection of 


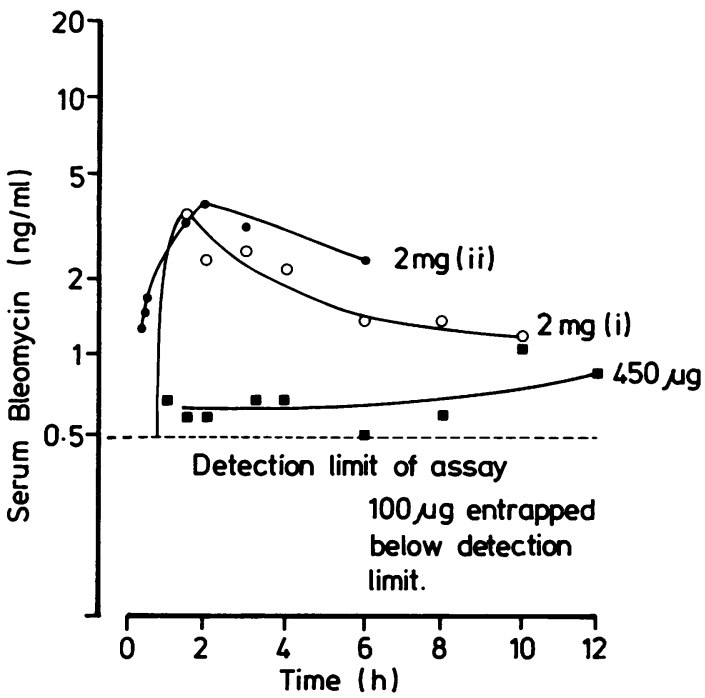

Fig. 4 Serum bleomycin levels following intracerebral injection of bleomycin entrapped within liposomes in 2 subjects with malignant gliomas (patients 1 and 3).

the free drug. The blood levels were reduced several fold and the urinary clearance to between a $1 / 4$ and a $1 / 2$ when bleomycin was given entrapped within liposomes as compared to the free drug. The $T^{1 / 2}$ in blood for bleomycin when injected into the tumour bed was approximately 3 times that when given intravenous ( $6 \mathrm{~h}$ as compared to $2 \mathrm{~h}$ ). The $T^{1 / 2}$ in blood for bleomycin when injected into the tumour bed and entrapped within liposomes was difficult to determine owing to the low levels encountered in blood and the fact that some free drug that had leaked out of the liposomes in storage would account for some of the early appearance of bleomycin in the blood.

\section{Discussion}

The dynamics of brain tumour growth are complex and consist of many mutually interacting phenomena which should be, although rarely are, taken into account when considering the therapeutic goal of reducing and if possible eradicating the neoplastic cells. " Since in addition so many factors have to be considered in the delivery of antimitotic drugs to cerebral neoplasms ${ }^{12}$ it is perhaps not surprising that the results of systemic chemotherapy in the treatment of gliomas has been disappointing. The biological variation in the the behaviour of cerebral gliomas of different histological type also suggests that each group must be considered separately with respect to planning chemotherapy and assessing

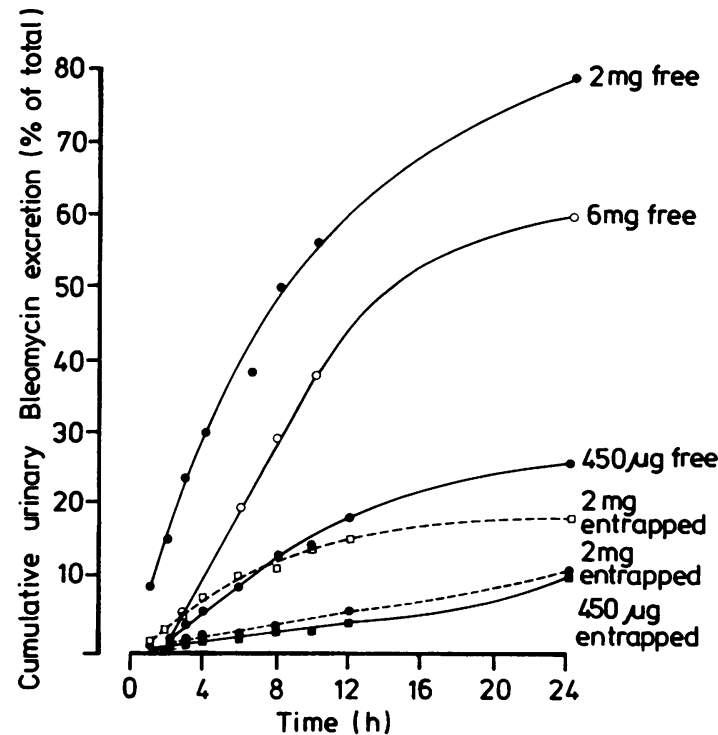

Fig. 5 Urinary excretion of bleomycin following intracerebral injection of bleomycin free and entrapped within liposomes in a subject with a malignant glioma (patient 3).

response to treatment..$^{13}$

Liposomes have recently been extensively studied as possible vehicles for delivering drugs to the required site of action in animal and human experiments. ${ }^{14}$ It has been demonstrated that liposomes of defined composition can be safely injected intracerebrally in the mouse ${ }^{15}$ and $\mathrm{rat}^{67}$ although certain types of liposome are toxic. ${ }^{15}$ The effectiveness of drugs entrapped within liposomes in cancer chemotherapy may be enhanced by recent developments that have enabled them to be targeted to the desired site by coupling antibody to the liposome surface. ${ }^{16}$

Bleomycin has been extensively studied as a chemotherapeutic agent with some success in the treatment of human ectodermally derived tumours. ${ }^{17}$ It is an antibiotic derived from Streptomyces verticullis shown to be particularly effective against certain types of cancer (skin, head and neck) and especially squamous cell carcinoma. Bleomycin when given intravenously to mice has a significant anti-tumour effect on gliomas with some preferential uptake into the tumour, but at high enough concentrations to produce complete cessation of tumour growth the animals lose weight and experience significant side effects. ${ }^{18}$ Similarly, high and sustained dosage of bleomycin in human cancer chemotherapy results in cutaneous and pulmonary complications. Since the major mode of action of bleomycin is to produce scission of DNA strands 
and thus hinder cell division ${ }^{19}$ it might be particularly useful in the treatment of human cerebral gliomas by acting on dividing gliomatous tissue with less effect on non-dividing neural tissue. These considerations suggest that an inert depot preparation of bleomycin injected locally into a tumour mass with sustained release of drug might be more effective than a similar dose given systemically and would enable a higher dose to be given with less likelihood of systemic toxicity.

We have confirmed the observations of Hayakawa $e t{ }^{20}$ that bleomycin is taken up by human glioma tissue in vivo after intravenous injection of therapeutic doses but at relatively low concentration. Dose response curves in vitro of a human glioma cell line (U251-MG) to bleomycin demonstrated that it was an effective chemotherapeutic agent but at relatively high concentration. ${ }^{s}$ The rapid clearance of bleomycin from the blood after intravenous injection indicated that high sustained levels of bleomycin at the tumour site could not be maintained without the likelihood of systemic side effects. Our preliminary observations have indicated that negatively charged liposomes of defined composition can be safely administered to human subjects with malignant gliomas through Ommaya reservoirs direct to the tumour bed without significant side effect. Although the desired high concentrations of bleomycin at the glioma tissue bed can be achieved by direct injection of the free drug through an Ommaya reservoir into the tumour, these studies suggest frequent injections would be required to maintain adequate therapeutic doses. However when bleomycin is injected into the glioma tumour bed entrapped in liposomes the blood levels achieved are approximately $10 \%$ of those obtained after injection of the free drug and the urinary clearance reduced. These results together with our in vitro studies on the rate of release of bleomycin from liposomes suggest that bleomycin can be given at high dosage entrapped within liposomes to act as a slow release depot preparation enabling high infrequent repeated dosages of drug to be given over a protracted treatment programme. We are currently refining and optimising an appropriate treatment schedule.

We thank St George's Hospital Medical Research Committee and the South West Thames Locally Organised Research Scheme for financial support which enabled these studies to be undertaken.

\section{References}

${ }^{1}$ Bergevin PR. Brain. In: Bergevin PR, Blom J, eds.
Guide to Therapeutic Oncology. Baltimore MD, Williams and Wilkins, 1979:492-6.

2 Steel GG. Growth kinetics of brain tumours. In: Thomas DGT, Graham DI, eds. Brain Tumours, Scientific Basis, Clinical Investigations and Current Therapy. London, Butterworths, 1980:10-20.

${ }^{3}$ Levin VA, Edwards MS. Chemotherapy of primary malignant gliomas. In: Thomas DGT, Graham DI, eds. Brain Tumours, Scientific Basis, Clinical Investigations and Current Therapy. London, Butterworths, 1980:344-58.

${ }^{4}$ Takeuchi K. A clinical trial of intravenous bleomycin in the treatment of brain tumours. Int J Clin Pharmacol 1975;12:419-26.

${ }^{5}$ Firth GB, Oliver AS, McKeran RO. Studies on the use of antimitotic drugs entrapped within liposomes and of their action on a human glioma cell line.J Neurol Sci 1984;63:153-65.

- Firth GB, Oliver AS, McKeran RO. Studies on the intracerebral injection of bleomycin free and entrapped within liposomes in the rat. J Neurol Neurosurg Psychiatry 1984;47:585-9.

7 Oliver AS, Firth GB, McKeran RO. Studies on the intracerebral injection of vincristine free and entrapped within liposomes in the rat. J Neurol Sci 1985;68:25-30.

${ }^{8}$ Salacinski P, Hope J, McLean C, Clement-Jones V, Sykes J, Price J, Lowry PJ. A new simple method which allows theoretical incorporation of radio-iodine into proteins and peptides without damage. J Endocrinol 1979;81:131.

"Szoka F, Papahadjopaulos D. Procedure for the preparation of liposomes with large internal aqueous space and high capture by reverse-phase evaporation. Proc Nat Acad Sci 1978;75:4194-8.

${ }^{10}$ Umezawa H. In: Carter SK, Crooke ST, eds. Bleomycin: Current Status and New Developments. Academic Press, 1978:15.

"McKeran RO, Wilde ED. Mathematical models of glioma growth. In: Thomas DGT, Graham DI, eds. Brain Tumours, Scientific Basis, Clinical Investigation and Current Therapy. London, Butterworths, 1980:182-93.

12 Blasberg RG. Pharmacodynamics and the blood-brain barrier, In: Evans AE, eds. Modern Concepts in Brain Tumour Therapy: Laboratory and Clinical Investigation. London, Castle House Publications Ltd. 1979: 18-26.

${ }^{13}$ McKeran RO, Thomas DGT. The clinical study of gliomas, In: Thomas DGT, Graham DI, eds. Brain Tumours, Scientific Basis, Clinical Investigation and Current Therapy. London, Butterworths, 1980:194230.

${ }^{14}$ Pittillo RF, Woolley C, Rice LS. Bleomycin, an anti tumour antibiotic-improved microbiological assay and tissue distribution studies in normal mice. Appl Microbiol 1971;22:564-6.

is Adams DH, Joyce G, Richardson IJ, Ryman BE, Wisniewshi HN. Liposome toxicity in the mouse central nervous system. J Neurol Sci 1977;31:173-9.

${ }^{16}$ Leserman LD, Machy P, Barbet J. Cell-specific drug transfer from liposomes bearing monoclonal anti- 
Intracerebral injection of drugs entrapped within liposomes in the treatment of human cerebral gliomas 1219 bodies. Nature 1981;293:226-8.

17 Umezawa H, Meada K, Takeuchi T, Okami Y. New antibiotics, bleomycin A and B J Antibiot., Ser A 1966; 19:200-9.

${ }^{18}$ Hayakawa T, Ushio Y, Mogami H, Horibata K. The uptake, distribution and anti-tumour activity of bleomycin in gliomas in the mouse. Eur J Cancer 1974; 10: 137-42.

19 Yamazaki Z, Muller WEG, Zahn RK. Action of bleomycin on programmed synthesis. Influence on enzymatic DNA, RNA and protein synthesis. Biochem Biophys Acta 1973;308:412-21.

${ }^{20}$ Hayakawa T, Ushio $\mathrm{Y}$, Morimoto $\mathrm{K}$, Hasegawa $\mathrm{H}$, Mogami H, Horibata K. Uptake of bleomycin by human brain tumours. J Neurol Neurosurg Psychiatry 1976;39:341-9. 